CLINICAL STUDY

\title{
Metformin improves polycystic ovary syndrome symptoms irrespective of pre-treatment insulin resistance
}

\author{
Susanne Tan, Susanne Hahn ${ }^{1}$, Sven Benson ${ }^{2}$, Tiina Dietz, Harald Lahner, Lars C Moeller, Markus Schmidt ${ }^{3}$, \\ Sigrid Elsenbruch ${ }^{2}$, Rainer Kimmig ${ }^{3}$, Klaus Mann and Onno E Janssen ${ }^{4}$ \\ Division of Endocrinology, Department of Medicine, University Hospital of Essen Medical School, Hufelandstr. 55, 45122 Essen, Germany, \\ ${ }^{1}$ Center for Endocrine and Metabolic Diseases, Wuppertal, Germany, ${ }^{2}$ Institute of Medical Psychology and Behavioral Immunobiology and ${ }^{3}$ Department of \\ Gynecology and Obstetrics, University Hospital of Essen Medical School, Essen, Germany and ${ }^{4}$ Division of Endocrinology, Metabolism and Molecular \\ Medicine, Department of Medicine Feinberg School of Medicine, Northwestern University, Chicago, Illinois, USA
}

(Correspondence should be addressed to S Tan; Email: susanne.tan@uk-essen.de)

\begin{abstract}
Objective: Insulin resistance (IR) and obesity are common features of the polycystic ovary syndrome (PCOS). Insulin-sensitizing agents have been shown to improve both reproductive and metabolic aspects of PCOS, but it remains unclear whether it is also beneficial in lean patients without pretreatment IR. The aim of this study was to determine the influence of metformin on the clinical and biochemical parameters of PCOS irrespective of the presence of basal obesity and IR.

Design: The effect of 6 months of metformin treatment was prospectively assessed in 188 PCOS patients, divided into three groups according to body mass index (BMI; lean: BMI $<25 \mathrm{~kg} / \mathrm{m}^{2}$, overweight: BMI $25-29 \mathrm{~kg} / \mathrm{m}^{2}$, and obese: $\mathrm{BMI} \geq 30 \mathrm{~kg} / \mathrm{m}^{2}$ ). Outcome parameters, which were also assessed in 102 healthy controls, included body weight, homeostasis model assessment for IR (HOMA-IR), fasting glucose and insulin levels, area under the curve of insulin response (AUCI), hyperandrogenism, and menstrual irregularities. Results: In comparison with the respective BMI-appropriate control groups, only obese but not lean and overweight PCOS patients showed differences in fasting insulin and HOMA-IR. Metformin therapy significantly improved all outcome parameters except fasting glucose levels. Subgroup analyses revealed that in the group of lean PCOS patients without pre-treatment IR, metformin significantly improved HOMA-IR $\left(1.7 \pm 1.0 \mathrm{vs} 1.1 \pm 0.7 \mu \mathrm{mol} / \mathrm{l} \times \mathrm{mmol} / \mathrm{l}^{2}\right)$ and fasting insulin levels $(7.7 \pm 4.2 \mathrm{vs} 5.4 \pm 3.9 \mathrm{mU} / \mathrm{l})$, in addition to testosterone levels $(2.6 \pm 0.9 \mathrm{vs} 1.8 \pm 0.7 \mathrm{nmol} / \mathrm{l})$, anovulation rate $(2.3 \mathrm{vs} 59.5 \%)$, and acne ( $31.8 \mathrm{vs}$ $11.6 \%$; all $P<0.017)$. In the overweight and obese PCOS groups, metformin also showed the expected beneficial effects.

Conclusion: Metformin improves parameters of IR, hyperandrogenemia, anovulation, and acne in PCOS irrespective of pre-treatment IR or obesity.
\end{abstract}

European Journal of Endocrinology 157 669-676

\section{Introduction}

Polycystic ovary syndrome (PCOS) is a common endocrine disorder affecting $6 \%$ of women of reproductive age (1-4). The current Rotterdam consensus defines PCOS as the presence of at least two out of the three criteria chronic anovulation, clinical and/or biochemical signs of hyperandrogenism, and polycystic ovaries (PCO), when other disorders of the pituitary, adrenals, or ovary have been excluded (5). Its clinical manifestations are oligomenorrhea or amenorrhea paired with infertility, hirsutism, acne, and alopecia. Many PCOS-affected women also suffer from insulin resistance (IR) (6-8) and obesity (9). Given the welldocumented association between PCOS and IR, insulinsensitizing agents have been used in the therapy of PCOS. To date, over 50 intervention studies have demonstrated a positive effect of metformin on both reproductive and metabolic aspects of PCOS (10-13). Nevertheless, the mechanisms underlying the beneficial effects of metformin in the treatment of PCOS remain incompletely understood. Improvement of IR by metformin may not only result from the well-known reduction of hepatic glucose production and increase of peripheral glucose utilization but also from a direct effect on ovarian steroidogenesis, as demonstrated by in vitro studies (14-16).

Since not all PCOS patients are obese or insulin resistant, it is not clear whether PCOS patients without IR also benefit from a therapy with insulin sensitizers. Several smaller studies have suggested positive effects of metformin irrespective of pre-treatment weight and/or presence of IR (Table 1). For example, Goldenberg et al. (31) demonstrated an equal improvement of menstrual irregularities both in insulin-resistant and insulinsensitive PCOS patients. To further address this important clinical question, the aim of this study was to determine whether metformin treatment improves 
Table 1 Published studies on metformin treatment in lean polycystic ovary syndrome (PCOS) women.

\begin{tabular}{|c|c|c|c|}
\hline Reference & Characterisation & Duration of treatment dose of metformin & Outcome parameters \\
\hline Maciel et al. (29) & $n=29$ lean versus obese PCOS patients & 6 months of $500 \mathrm{mg}$ TID & $\begin{array}{l}\text { Significant reduction of parameters of insulin } \\
\text { resistance (fasting insulin, AUCl), androgen } \\
\text { levels (total and free testosterone, androstene- } \\
\text { dione) in lean PCOS patients. In obese PCOS } \\
\text { patients only improvement of free testosterone } \\
\text { levels, while all other parameters did not change }\end{array}$ \\
\hline Kumari et al. (30) & $\begin{array}{c}n=17 \text { lean versus } 17 \text { obese PCOS patients BMI } \\
24 \mathrm{vs} 36 \mathrm{~kg} / \mathrm{m}^{2} \text { fasting insulin } 12 \mathrm{vs} 21 \mathrm{mU} / \mathrm{l}\end{array}$ & 12 weeks of $500 \mathrm{mg}$ TID & $\begin{array}{l}\text { Greater improvement of ovulation rate (88 vs } 29 \% \text { ) } \\
\text { and pregnancy rate (65 vs } 18 \% \text { ) in the lean } \\
\text { PCOS group }\end{array}$ \\
\hline Goldenberg et al. (31) & $\begin{array}{l}n=32 \text { top versus } 35 \text { bottom quintile HOMA-IR } \\
\text { PCOS patients }\end{array}$ & $\begin{array}{l}12 \text { months of } 850 \mathrm{mg} \text { TID in addition: diet with } \\
6300-8400 \mathrm{~J} / \mathrm{day}, 26 \% \text { protein, } 44 \% \text { carbo- } \\
\text { hydrates }\end{array}$ & $\begin{array}{l}\text { Significant reduction of body weight, parameters of } \\
\text { insulin resistance (fasting insulin, HOMA-IR, } \\
\text { insulin secretion), and ovulation rate in both } \\
\text { groups with smaller but significant reduction in } \\
\text { the bottom insulin-resistant group concerning } \\
\text { insulin resistance and without group effect } \\
\text { concerning ovulation rate }\end{array}$ \\
\hline Yilmaz et al. (32) & $\begin{array}{l}n=20 \text { lean versus } 20 \text { obese each in the metformin } \\
\text { and rosiglitazone group }\end{array}$ & $\begin{array}{l}12 \text { weeks of metformin: } 850 \mathrm{mg} \text { BID rosiglitazone: } \\
4 \mathrm{mg} / \text { day }\end{array}$ & $\begin{array}{l}\text { Significant reduction in parameters of insulin } \\
\text { resistance (HOMA-IR, AUCI, fasting insulin, C- } \\
\text { peptide) as well as improvement of ovulation } \\
\text { rate in all four groups. No effect of metformin on } \\
\text { androgens in lean or obese PCOS patients } \\
\text { (testosterone, androstenedione, DHEAS) }\end{array}$ \\
\hline Marcondes et al. (33) & $\begin{array}{c}n=12 \text { normal weight PCOS patients BMI } 21.5 \pm \\
1.65 \mathrm{~kg} / \mathrm{m}^{2}\end{array}$ & $850 \mathrm{mg}$ TID for 4 months & $\begin{array}{l}\text { No effect on BMI or hirsutism score, significant } \\
\text { improvement of ovulation rate, testosterone } \\
\text { levels, and insulin resistance parameters } \\
\text { (fasting insulin, } \mathrm{AUCl}, \mathrm{HOMA}-\mathrm{IR} \text { ) as well as LH } \\
\text { decrease and } \mathrm{FSH} \text { increase }\end{array}$ \\
\hline Orio et al. (34) & $\begin{array}{l}n=50 \text { normal weight PCOS patients BMI 25.6 } \\
4.2 \mathrm{~kg} / \mathrm{m}^{2}\end{array}$ & $850 \mathrm{mg} \mathrm{BID}$ for 6 months & $\begin{array}{l}\text { Improvement of free androgen index, fasting } \\
\text { insulin, HOMA-IR, AUCl, and white blood cell } \\
\text { count. Normalisation of menstrual cycles by } \\
91.1 \% \text {. No significant change in hirsutism score, } \\
\text { testosterone, and androstenedione levels }\end{array}$ \\
\hline
\end{tabular}


clinical and biochemical parameters of PCOS irrespective of the presence of obesity and IR prior to treatment.

\section{Materials and methods}

\section{Study design and outcome parameters}

PCOS patients were evaluated at baseline and following treatment with metformin in a weight-adapted dose for 6 months (body weight <60 kg: $500 \mathrm{mg}$ metformin twice a day (BID), 60-100 kg: $850 \mathrm{mg}$ BID, and $\geq 100 \mathrm{~kg}$ or BMI $\geq 30 \mathrm{~kg} / \mathrm{m}^{2}: 1000 \mathrm{mg}$ BID). Outcome parameters included ovulation rate, presence of acne, alopecia, testosterone levels, and hirsutism, in addition to changes in weight as well as in parameters of IR.

\section{Recruitment of participants, inclusion, and exclusion criteria}

PCOS patients $(n=188)$ were recruited from the outpatient clinics of the Division of Endocrinology, Department of Medicine, and the Department of Gynecology at the University of Duisburg-Essen. Some patients were also attracted by the clinic's PCOS homepage (www.pcosyndrom.de). PCOS was defined according to the 2003 Rotterdam criteria (5). Age-matched healthy controls $(n=102)$ were recruited from a mandatory screening program for employees instituted at the University of Duisburg-Essen. Exclusion criteria in controls included any known medical condition or disease. In addition, care was taken to exclude all NIH criteria in controls. Specifically, control women were required to have a normal menstrual cycle (i.e. shorter than 35 days), testosterone levels lower than $2.0 \mathrm{nmol} / \mathrm{l}$ and/or dehydroepiandrostenedione sulfate (DHEAS) lower than $270 \mu \mathrm{g} / \mathrm{dl}$ and/or androstenedione lower than $3.3 \mathrm{ng} / \mathrm{ml}$, and no hirsutism, acne, or alopecia. The study protocol was approved by the Ethics Committee of the University of Duisburg-Essen. All participants gave written informed consent before entering the study. All study participants were not taking any medication at least 3 months before entering the study.

\section{Data collection}

All women underwent a personal interview with a physician, including an evaluation of demographic characteristics, previous medication, physical examination, and blood sampling. Based on the criteria derived from the 2003 Rotterdam consensus conference (5), diagnosis of PCOS was established when two of the following criteria were present: oligomenorrhea (cycles lasting longer than 35 days) or amenorrhea (less than two menstrual cycles in the past 6 months), clinical or biochemical signs of hyperandrogenism (hirsutism) with a Ferriman-Gallwey score (FG) of more than 7 (18) or obvious acne or alopecia (19) or an elevated total testosterone (normal range $<2.0 \mathrm{nmol} / \mathrm{l}$ ) and/or DHEAS (normal range 45-270 $\mu \mathrm{g} / \mathrm{dl}$ ) and/or androstenedione (normal range $0.2-3.3 \mathrm{ng} / \mathrm{ml}$ ) and PCO (at least one ovary with at least 12 follicles of a diameter of $2-9 \mathrm{~mm}$ or a volume $>10 \mathrm{ml}$ ), and other pituitary, adrenal, or ovarian diseases could be excluded. Therefore, laboratory analysis of luteinizing hormone (LH), folliclestimulating hormone (FSH), estradiol, prolactin, cortisol, adrenocorticotrophin (ACTH), thyrotrophin (TSH), insulin-like growth factor, androstenedione, and dehydroepiandrosterone sulfate was completed. In addition, an ACTH test with measurement of 17-hydroxyprogesterone was accomplished. When the stimulated value (after $60 \mathrm{~min})$ was $>10 \mathrm{ng} / \mathrm{ml}$, a genetic analysis (21-hydroxylase deficiency) was added.

Hirsutism was routinely evaluated independently by two physicians using the common modified FG. This method to assess hirsutism requires the visual scoring of the extent of terminal hairs in nine body areas, named 1) upper lip, 2) chin, 3) chest, 4) upper abdomen, 5) lower abdomen, 6) upper back, 7) lower back, 8) thighs, and 9) upper arms. The lower arms and lower legs were not included in the hair assessment. Each area was scored from 0 to 4 , resulting in a possible maximum score of 36 . Hirsutism was diagnosed when a score above 7 was evaluated. FG scores never differed by more than 2 , and whenever ratings were not identical, the patient was re-evaluated by a third physician and the median value was then used.

Body mass index (BMI) was calculated as weight $/(\text { height })^{2}$ in $\left(\mathrm{kg} / \mathrm{m}^{2}\right)$. Parameters of IR and $\beta$-cell function were evaluated using a 3-h oral glucose tolerance test. After an overnight fast of $12 \mathrm{~h}$ patients ingested $75 \mathrm{~g}$ glucose and had their glucose and insulin levels determined at baseline and at 30, 60, 90, 120, and $180 \mathrm{~min}$. IR was defined by the homeostasis model assessment (HOMA) model $(20,21)$ and hyperinsulinemia by calculating the area under the insulin response curve (AUCI) (22). IR in control women was evaluated by fasting glucose, fasting insulin, and the HOMA model.

\section{Biochemical analyses}

Automated chemiluminescence immunoassay systems were used for the determination of LH, FSH, ACTH, TSH, testosterone, estradiol, cortisol, free thyroxine, blood glucose (ADVIA Centaur, Bayer Vital, Fernwald, Germany), dehydroepiandrosterone sulfate, androstenedione, sex hormone-binding globulin, insulin (IMMULITE 2000, DPC Biermann, Bad Nauheim, Germany), and insulin-like growth factor (Nichols Advantage, Nichols Institute Diagnostics, Bad Vilbel, Germany). 17-Hydroxyprogesterone was measured by the Biosource 17- $\alpha-\mathrm{OH}-\mathrm{RIA}-\mathrm{CT}$ kit (Biosource International, Camarillo, CA, USA; analytical sensitivity $0.02 \mathrm{ng} / \mathrm{ml}$ ) provided by IBL Hamburg (IBL, Gesellschaft für Immunchemie und Immunbiologie, Hamburg, Germany). Intraassay variation was $<5 \%$ and interassay variation was $<8 \%$ for all parameters. 


\section{Statistical analyses}

PCOS patients and controls were each divided into three subgroups according to BMI (lean: BMI $<25 \mathrm{~kg} / \mathrm{m}^{2}$, overweight: BMI 25-29 kg/m², obese: BMI $\geq 30 \mathrm{~kg} / \mathrm{m}^{2}$ ). Statistical analyses were completed in three consecutive steps.

1) The goal of the first analysis was to establish differences between untreated PCOS and healthy controls, which was particularly relevant for the lean PCOS group. Therefore, in a first step, pre-treatment values of PCOS patients were compared with controls using twofactorial ANOVA to assess the effects of diagnosis and BMI-group. Subsequently, within each weight group, means of patients were compared with controls using post hoc comparisons of means. In doing so, $\alpha$ levels were corrected for inflation of $\alpha$ error by multiple testing by applying the conservative Bonferroni method, which divides the $\alpha$ level of 0.05 by the number of tests for each variable (in this case given three groups: $0.05 / 3=0.017)$. Hence, in evaluating the results of the post hoc comparisons, only comparisons with a $P$ level that was smaller than 0.017 were considered statistically significant.

2) The aim of the second set of analyses was to establish treatment effects of metformin based on pre-treatment weight and IR in PCOS. Therefore, the effects of metformin in PCOS were addressed using two-factorial ANOVA with the factors time (pre-treatment, posttreatment) and BMI group, again followed by $\alpha$-corrected post hoc comparisons of means within each weight group. For repeated assessment of frequency distributions given dichotomous variables (e.g. acne, alopecia, menstrual disturbances), no statistical method that is equivalent to the ANOVA exists; therefore, McNemar tests for repeated measurements of dichotomous variables in a sample were applied to address the effects of treatment. The $P$ levels were again corrected here using the Bonferroni method described above.

3) Finally, post-treatment values in PCOS were compared with controls to establish whether or not metformin achieved a complete normalization. This was again accomplished with two-factorial ANOVA with the factors diagnosis and weight group, followed by post hoc comparisons of patient versus control means with $\alpha$-correction as described above. For the dichotomous variables, $\chi^{2}$ tests were applied. Data are presented as mean \pm s.D. or as number and percent affected.

\section{Results}

\section{Baseline parameters}

Of the total of $N=188$ PCOS patients, $N=44$ were in the lean group (mean BMI: 22.0 \pm 1.6 ), $N=42$ were in the overweight group (mean BMI: $26.8 \pm 1.5$ ), and $N=102$ were in the obese group (mean BMI: 38.1 \pm 6.0 ) (Table 2). Out of the total of $N=102$ healthy women, $N=66$ were in the lean group (mean BMI: $21.5 \pm 1.6$ ), $N=24$ in the overweight group (mean BMI: $26.7 \pm 1.4$ ), and $N=12$ were in the obese group (mean BMI: 34.4 \pm 5.1 ). In comparison with the respective BMI-appropriate control group, lean and overweight PCOS patients showed no differences in fasting insulin, HOMA-IR, and fasting glucose levels. On the other hand, obese PCOS patients had similar fasting glucose but significant higher fasting insulin and HOMA-IR levels compared with obese controls (Table 2). As expected, when compared with controls, all PCOS patient groups demonstrated significantly higher testosterone levels and FG scores.

\section{Effects of metformin treatment}

Overall, 6 months of metformin therapy significantly improved all outcome parameters, indicated by significant ANOVA time effects (see Table 3), with the exception of fasting glucose levels. Interestingly, subgroup analyses revealed that in the group of lean PCOS patients without pre-treatment IR (see above), metformin significantly improved HOMA-IR and fasting insulin levels, in addition to testosterone levels, menstrual irregularities, and acne (all $P<0.017$, see Table 3). In the overweight and obese PCOS groups, metformin also showed the expected beneficial effects, including significant improvements in weight, HOMA-IR, AUCI, fasting insulin as well as testosterone (all $P<0.017$ ) (Tables 3 and 4 ).

A comparison of treated PCOS patients with the appropriate BMI control groups revealed that treatment normalized parameters of IR in all PCOS BMI groups, and even improved fasting insulin levels beyond normal values in lean PCOS (Table 4). On the other hand, hyperandrogenism and/or hirsutism, as well as the prevalence of menstrual cycle irregularities, acne, and alopecia remained significantly more pronounced in patients even following treatment (Table 4).

\section{Discussion}

PCOS is one of the most common endocrine disorders of women of reproductive age. Since the role of IR in the pathogenesis of PCOS has been established, many interventional studies have demonstrated a positive effect of insulin-sensitizing agents in the treatment of PCOS. For example, Hahn et al. (11) pointed out a positive effect of metformin on hyperandrogenism, chronic anovulation, and IR in a German PCOS cohort. Palomba et al. $(13,23)$ reported a significant improvement of ovulation, pregnancy and ovulation rate in comparison with clomiphene and ovarian drilling. Many metformin intervention studies from Italy, Finland, UK, and the United States demonstrated a positive effect of metformin on body weight and/or BMI $(17,24-27)$. An improvement of body weight, low density 


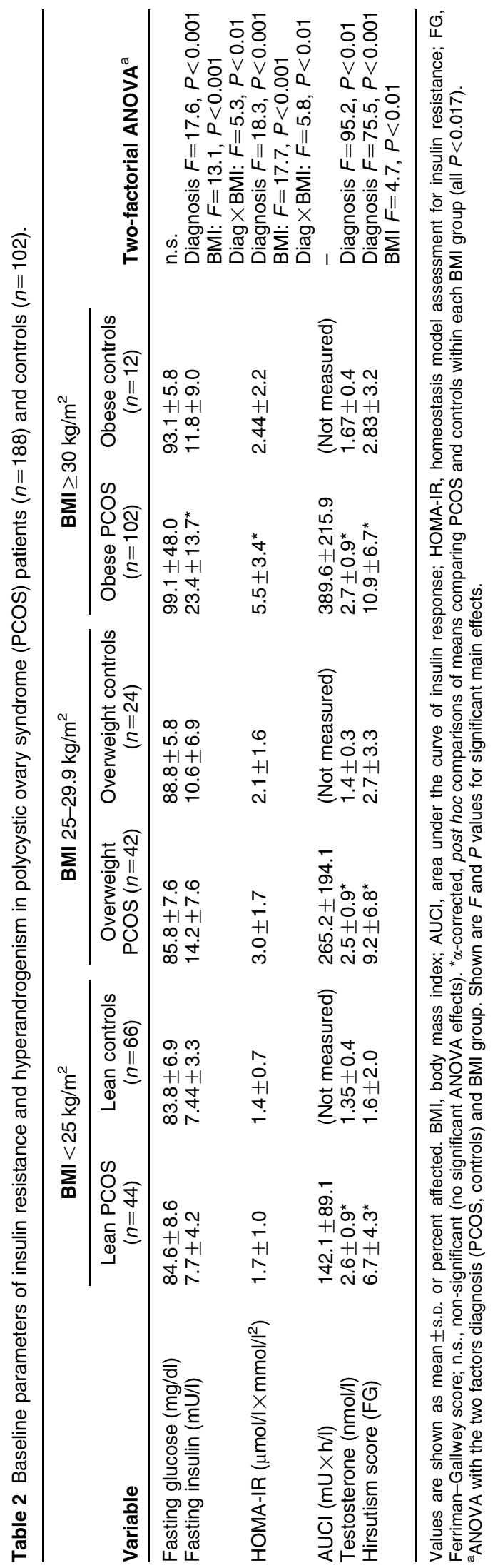

lipoprotein (LDL)-cholesterol and systolic blood pressure has been shown by an analysis of 13 randomized interventional studies summarized in a Cochrane review (12). In accordance with these studies, our results show that PCOS patients benefit from metformin treatment with regard to hyperandrogenism, menstrual disturbances, acne, and IR. Similar to the significant BMI reduction reported in a British (24) and an American study (28) metformin caused a significant weight reduction in our PCOS cohort of overweight and obese patients.

Since not all PCOS patients are obese or insulin resistant, it has thus far remained unclear whether PCOS patients without evidence of IR would also benefit from a therapy with insulin sensitizers. Indeed, our sample of lean PCOS patients did not differ from lean controls in BMI or levels of fasting insulin and HOMA-IR. Interestingly, in response to metformin treatment, this group of lean PCOS patients clearly showed significant improvements not only in androgen levels, acne, and menstrual irregularities, but also in HOMA-IR, AUC-I, and fasting insulin levels. Hence, even in patients who do not show basal elevation in parameters of IR and present with normal BMI, there is a clear benefit of metformin. This finding is in accordance with several smaller previous studies, which however did not include healthy controls (Table 1). For example, in a Brazilian study with 29 PCOS patients hyperandrogenemia was reduced by treatment with $500 \mathrm{mg}$ three times daily (TID) metformin (29). In addition, lean PCOS patients benefitted from metformin through a reduction of AUCI and fasting insulin. Maciel et al. (29) concluded that lean PCOS patients respond even better to treatment with metformin than obese patients. Kumari et al. (30) demonstrated in a study including 17 lean and 17 obese PCOS patients treated with $1500 \mathrm{mg}$ metformin daily that ovulation and pregnancy rates were higher in the lean PCOS group. These studies are in agreement with our study data, showing a positive effect of metformin therapy on endocrine and metabolic variables even in lean and insulin-sensitive women. Harborne et al. (17) demonstrated a dose-dependent effect of metformin, the divergent effect concerning the outcome of our overweight and obese patients may result from the higher dose applied to our patients. Goldenberg et al. (31) divided their PCOS population into quintiles according to HOMA-IR as a parameter for IR and compared the bottom and top quintile after 1 year of intervention with metformin and diet. They demonstrated an improvement of menstrual cyclicity in the bottom quintile that did not differ from that of the top quintile. Our study confirms the independence from IR of metformin action on menstrual cyclicity in PCOS patients.

Several in vitro studies have revealed some aspects of the mechanisms presumably underlying metformin action. Using cultured ovarian cells from women undergoing bilateral salpingoophorectomy, an inhibition of progesterone and estradiol in granulosa cells and androstenedione in theca cells by metformin has been 
Table 3 Metformin treatment effects in polycystic ovary syndrome (PCOS).

\begin{tabular}{|c|c|c|c|c|c|c|c|}
\hline \multirow[b]{2}{*}{ Variable } & \multicolumn{2}{|c|}{$\begin{array}{c}\text { Lean PCOS } \\
\text { BMI }<25 \mathrm{~kg} / \mathrm{m}^{2}(n=44)\end{array}$} & \multicolumn{2}{|c|}{$\begin{array}{c}\text { Overweight PCOS } \\
\text { BMI } 25-29,9 \mathrm{~kg} / \mathrm{m}^{2}(n=42)\end{array}$} & \multicolumn{2}{|c|}{$\begin{array}{c}\text { Obese Pcos } \\
\mathrm{BMI} \geq 30 \mathrm{~kg} / \mathrm{m}^{2}(n=102)\end{array}$} & \multirow[b]{2}{*}{$\begin{array}{l}\text { Two-factorial ANOVA or } \\
\text { McNemar Test }^{\mathrm{a}}\end{array}$} \\
\hline & Baseline & $\begin{array}{l}\text { After } 6 \text { months of } \\
\text { metformin }\end{array}$ & Baseline & $\begin{array}{l}\text { After } 6 \text { months of } \\
\text { metformin }\end{array}$ & Baseline & $\begin{array}{l}\text { After } 6 \text { months of } \\
\text { metformin }\end{array}$ & \\
\hline Body weight (kg) & $62.9 \pm 8.3$ & $61.6 \pm 7.8$ & $74.2 \pm 6.6$ & $70.9 \pm 8.4^{*}$ & $105.7 \pm 18.7$ & $99.2 \pm 19.0^{*}$ & $\begin{array}{l}\text { Time } F=19.1, P<0.001 \\
\text { BMI } F=155.3, P<0.001 \\
\text { Time } \times \text { BMI } F=4.1, P<0.05\end{array}$ \\
\hline BMI $\left(\mathrm{kg} / \mathrm{m}^{2}\right)$ & $22.0 \pm 1.6$ & $21.6 \pm 1.6$ & $26.8 \pm 1.5$ & $25.8 \pm 2.3^{*}$ & $38.1 \pm 6.0$ & $36.7 \pm 8.9$ & $\begin{array}{l}\text { Time } F=4.5, P<0.05 \\
\text { BMI } F=178.4, P<0.001\end{array}$ \\
\hline Fasting glucose (mg/dl) & $84.6 \pm 8.6$ & $82.6 \pm 8.2$ & $85.8 \pm 7.6$ & $83.4 \pm 7.4$ & $99.1 \pm 48.0$ & $90.0 \pm 18.0$ & BMI $F=3.3, P<0.05$ \\
\hline Fasting insulin (mU/l) & $7.7 \pm 4.2$ & $5.4 \pm 3.9^{*}$ & $14.2 \pm 7.6$ & $9.8 \pm 5.2^{*}$ & $23.4 \pm 13.7$ & $16.9 \pm 9.8^{*}$ & $\begin{array}{l}\text { Time } F=34.6, P<0.001 \\
\text { BMI } F=33.8, P<0.001\end{array}$ \\
\hline HOMA-IR $\left(\mu \mathrm{mol} / / \times \mathrm{mmol} / /^{2}\right)$ & $1.7 \pm 1.0$ & $1.1 \pm 0.7^{*}$ & $3.0 \pm 1.7$ & $2.0 \pm 1.2^{*}$ & $5.5 \pm 3.4$ & $3.7 \pm 2.2^{*}$ & $\begin{array}{l}\text { Time } F=38.3, P<0.001 \\
\text { BMI } F=42.3, P<0.001 \\
\text { Time } \times \text { BMI } F=4.0, P<0.05\end{array}$ \\
\hline $\mathrm{AUCl}(\mathrm{mU} \times \mathrm{h} / \mathrm{l})$ & $142.1 \pm 89.1$ & $136.3 \pm 69.4$ & $265.2 \pm 194.1$ & $197.2 \pm 106.5^{\star}$ & $389.6 \pm 215.9$ & $293.5 \pm 153.7^{*}$ & $\begin{array}{l}\text { Time } F=17.3, P<0.001 \\
\text { BMI } F=28.9, P<0.001 \\
\text { Time } \times \text { BMI } F=4.1, P<0.05\end{array}$ \\
\hline Testosterone (nmol//) & $2.6 \pm 0.9$ & $1.8 \pm 0.7^{*}$ & $2.5 \pm 0.9$ & $1.9 \pm 0.6^{\star}$ & $2.7 \pm 0.9$ & $2.1 \pm 0.8^{*}$ & Time $F=78.2, P<0.001$ \\
\hline Hirsutism score (FG) & $6.7 \pm 4.3$ & $6.2 \pm 4.6$ & $9.2 \pm 6.8$ & $8.3 \pm 5.4$ & $10.9 \pm 6.7$ & $10.6 \pm 6.8$ & $\begin{array}{l}\text { Time }=4.9, P<0.05 \\
\text { BMI } F=7.7, P<0.001\end{array}$ \\
\hline Normal menstrual cycles (\%) & 2.3 & $59.5^{\star}$ & 7.1 & $46.2^{*}$ & 3.9 & $50.0^{*}$ & McNemar time $P<0.001$ \\
\hline Acne (\%) & 31.8 & $11.6^{\star}$ & 53.7 & $22.0^{\star}$ & 42.2 & $27.8^{*}$ & McNemar time $P<0.001$ \\
\hline Alopecia (\%) & 18.2 & 18.2 & 22.5 & 24.4 & 35.3 & 25.8 & McNemar n.s. \\
\hline
\end{tabular}

Values are shown as mean \pm S.D. or percent affected. BMI, body mass index; AUCI, area under the curve of insulin response; HOMA-IR, homeostasis model assessment for insulin resistance; FG, FerrimanGallwey score; n.s., no significant effects. ${ }^{*} \alpha$-corrected, post hoc comparisons of means comparing PCOS pre-treatment versus 6 -month post-treatment within each BMI group (all $P<0.017$ ). ANOVA with the two factors time (pre-treatment, 6-month post-treatment) and BMI group. Shown are $F$ and $P$ values for significant main effects as well as for significant interactions between treatment effects and BMI group (Time $\times \mathrm{BMI}$ ). For dichotomous variables, the McNemar test was applied to address treatment effects (Time). 


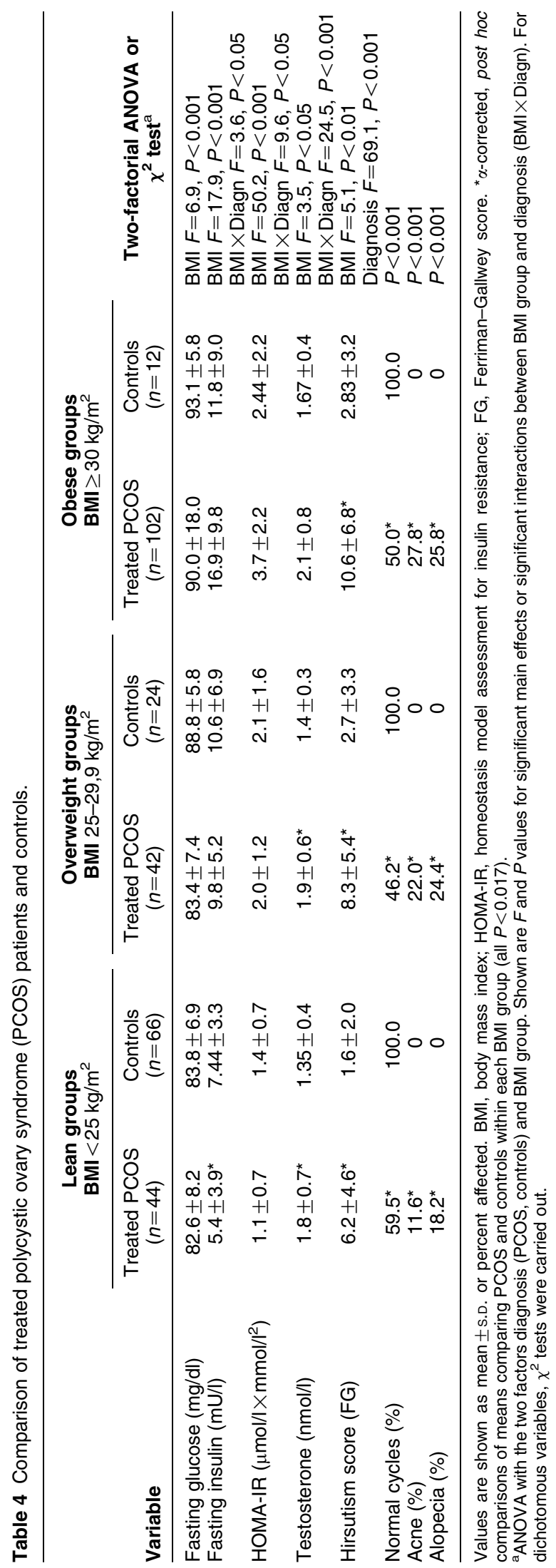

demonstrated (14). Furthermore, ovarian steroidogenesis in bovine granulosa cells was reportedly inhibited by decreased phosphorylation of MAPK3/MAPK14 by metformin (16). In Wister rats with androgen-induced PCOS, an inhibition of DHEA-induced testosterone concentration by metformin application has also been shown (15). Together, these studies suggest a direct inhibitory effect of metformin on ovarian steroidogenesis.

While the exact mechanism of metformin action is still unclear, it appears that besides reducing IR and thus hyperinsulinemia, metformin has significant effects that are independent from pre-treatment IR.

\section{References}

1 Asuncion M, Calvo RM, San Millan JL, Sancho J, Avila S \& EscobarMorreale HF. A prospective study of the prevalence of the polycystic ovary syndrome in unselected Caucasian women from Spain. Journal of Clinical Endocrinology and Metabolism 200085 2434-2438.

2 Azziz R, Woods KS, Reyna R, Key TJ, Knochenhauer ES \& Yildiz BO. The prevalence and features of the polycystic ovary syndrome in an unselected population. Journal of Clinical Endocrinology and Metabolism 200489 2745-2749.

3 Carmina E \& Lobo RA. Polycystic ovary syndrome (PCOS): arguably the most common endocrinopathy is associated with significant morbidity in women. Journal of Clinical Endocrinology and Metabolism 199984 1897-1899.

4 Diamanti-Kandarakis E, Kouli CR, Bergiele AT, Filandra FA, Tsianateli TC, Spina GG, Zapanti ED \& Bartzis MI. A survey of the polycystic ovary syndrome in the Greek island of Lesbos: hormonal and metabolic profile. Journal of Clinical Endocrinology and Metabolism $1999 \mathbf{8 4} 4006-4011$.

5 ESHRE/ASRM. Revised 2003 consensus on diagnostic criteria and long-term health risks related to polycystic ovary syndrome (PCOS). Human Reproduction 200419 41-47.

6 Dunaif A. Insulin action in the polycystic ovary syndrome. Endocrinology and Metabolism Clinics of North America 199928 341-359.

7 Dunaif A \& Finegood DT. Beta-cell dysfunction independent of obesity and glucose intolerance in the polycystic ovary syndrome. Journal of Clinical Endocrinology and Metabolism 199681 942-947.

8 Dunaif A, Segal KR, Futterweit W \& Dobrjansky A. Profound peripheral insulin resistance, independent of obesity, in polycystic ovary syndrome. Diabetes 198938 1165-1174.

9 Evans DJ, Hoffmann RG, Kalkhoff RK \& Kissebah AH. Relationship of androgenic activity to body fat topography, fat cell morphology, and metabolic aberrations in premenopausal women. Journal of Clinical Endocrinology and Metabolism 198357 304-310.

10 Glueck CJ, Morrison JA, Friedman LA, Goldenberg N, Stroop DM \& Wang P. Obesity, free testosterone, and cardiovascular risk factors in adolescents with polycystic ovary syndrome and regularly cycling adolescents. Metabolism 200655 508-514.

11 Hahn S, Quadbeck B, Elsenbruch S, Gartner R, Finke R, Mann K \& Janssen OE. Metformin, an efficacious drug in the treatment of polycystic ovary syndrome. Deutsche Medizinische Wochenschrift 2004129 1059-1064.

12 Lord JM, Flight IH \& Norman RJ. Insulin-sensitising drugs (metformin, troglitazone, rosiglitazone, pioglitazone, D-chiro-inositol) for polycystic ovary syndrome. Cochrane Database of Systematic Reviews 20033 CD003053.

13 Palomba S, Orio F, Falbo A, Manguso F, Russo T, Cascella T, Tolino A, Carmina E, Colao A \& Zullo F. Prospective parallel randomized, double-blind, double-dummy controlled clinical trial comparing clomiphene citrate and metformin as the first-line 
treatment for ovulation induction in nonobese anovulatory women with polycystic ovary syndrome. Journal of Clinical Endocrinology and Metabolism 200590 4068-4074.

14 Mansfield R, Galea R, Brincat M, Hole D \& Mason H. Metformin has direct effects on human ovarian steroidogenesis. Fertility and Sterility $2003 \mathbf{7 9}$ 956-962.

15 Misugi T, Ozaki K, El Beltagy K, Tokuyama O, Honda K \& Ishiko O. Insulin-lowering agents inhibit synthesis of testosterone in ovaries of DHEA-induced PCOS rats. Gynecologic and Obstetric Investigation $200661208-215$.

16 Tosca L, Solnais P, Ferre P, Foufelle F \& Dupont J. Metformin-induced stimulation of adenosine $5^{\prime}$ monophosphate-activated protein kinase (PRKA) impairs progesterone secretion in rat granulosa cells. Biology of Reproduction 200675 342-351.

17 Harborne LR, Sattar N, Norman JE \& Fleming R. Metformin and weight loss in obese women with polycystic ovary syndrome: comparison of doses. Journal of Clinical Endocrinology and Metabolism $2005904593-4598$.

18 Ferriman D \& Gallwey JD. Clinical assessment of body hair growth in women. Journal of Clinical Endocrinology and Metabolism 196121 1440-1447.

19 Ludwig E. Classification of the types of androgenetic alopecia (common baldness) occurring in the female sex. British Journal of Dermatology 197797 247-254.

20 Hermans MP, Levy JC, Morris RJ \& Turner RC. Comparison of insulin sensitivity tests across a range of glucose tolerance from normal to diabetes. Diabetologia 199942 678-687.

21 Hermans MP, Levy JC, Morris RJ \& Turner RC. Comparison of tests of beta-cell function across a range of glucose tolerance from normal to diabetes. Diabetes $1999 \mathbf{4 8} 1779-1786$.

22 Phillips DI, Clark PM, Hales CN \& Osmond C. Understanding oral glucose tolerance: comparison of glucose or insulin measurements during the oral glucose tolerance test with specific measurements of insulin resistance and insulin secretion. Diabetic Medicine 199411 286-292.

23 Palomba S, Orio F, Nardo LG, Falbo A, Russo T, Corea D, Doldo P, Lombardi G, Tolino A, Colao A \& Zullo F. Metformin administration versus laparoscopic ovarian diathermy in clomiphene citrateresistant women with polycystic ovary syndrome: a prospective parallel randomized double-blind placebo-controlled trial. Journal of Clinical Endocrinology and Metabolism 200489 4801-4809.

24 Fleming R, Hopkinson ZE, Wallace AM, Greer IA \& Sattar N. Ovarian function and metabolic factors in women with oligomenorrhea treated with metformin in a randomized double blind placebocontrolled trial. Journal of Clinical Endocrinology and Metabolism 200287 569-574.

25 Morin-Papunen L, Rautio K, Ruokonen A, Hedberg P, Puukka M \& Tapanainen JS. Metformin reduces serum C-reactive protein levels in women with polycystic ovary syndrome. Journal of Clinical Endocrinology and Metabolism $2003 \mathbf{8 8} 4649-4654$.
26 Pasquali R, Gambineri A, Biscotti D, Vicennati V, Gagliardi L, Colitta D, Fiorini S, Cognigni GE, Filicori M \& Morselli-Labate AM. Effect of long-term treatment with metformin added to hypocaloric diet on body composition, fat distribution, and androgen and insulin levels in abdominally obese women with and without the polycystic ovary syndrome. Journal of Clinical Endocrinology and Metabolism $2000852767-2774$.

27 Vandermolen DT, Ratts VS, Evans WS, Stovall DW, Kauma SW \& Nestler JE. Metformin increases the ovulatory rate and pregnancy rate from clomiphene citrate in patients with polycystic ovary syndrome who are resistant to clomiphene citrate alone. Fertility and Sterility 200175 310-315.

28 Nestler JE \& Jakubowicz DJ. Decreases in ovarian cytochrome $\mathrm{P} 450 \mathrm{c} 17$ alpha activity and serum free testosterone after reduction of insulin secretion in polycystic ovary syndrome. New England Journal of Medicine 1996335 617-623.

29 Maciel GA, Soares Junior JM, Alves da Motta EL, Abi Haidar M, de Lima GR \& Baracat EC. Nonobese women with polycystic ovary syndrome respond better than obese women to treatment with metformin. Fertility and Sterility 200481 355-360.

30 Kumari AS, Haq A, Jayasundaram R, Abdel-Wareth LO, Al Haija SA \& Alvares M. Metformin monotherapy in lean women with polycystic ovary syndrome. Reproductive Biomedicine Online 2005 10 100-104

31 Goldenberg N, Glueck CJ, Loftspring M, Sherman A \& Wang P. Metformin-diet benefits in women with polycystic ovary syndrome in the bottom and top quintiles for insulin resistance. Metabolism 200554 113-121.

32 Yilmaz M, Biri A, Karakoc A, Toruner F, Bingol B, Cakir N, Tiras B, Ayvaz G \& Arslan M. The effects of rosiglitazone and metformin on insulin resistance and serum androgen levels in obese and lean patients with polycystic ovary syndrome. Journal of Endocrinological Investigation $2005 \mathbf{2 8}$ 1003-1008.

33 Marcondes JA, Yamashita SA, Maciel GA, Baracat EC \& Halpern A. Metformin in normal-weight hirsute women with polycystic ovary syndrome with normal insulin sensitivity. Gynecological Endocrinology 200723 273-278.

34 Orio F, Manguso F, Di Biase S, Falbo A, Giallauria F, Labella D, Tolino A, Lombardi G, Colao A \& Palomba S. Metformin administration improves leukocyte count in women with polycystic ovary syndrome: a 6-month prospective study. European Journal of Endocrinology 2007157 69-73.

Received 19 July 2007

Accepted 3 September 2007 